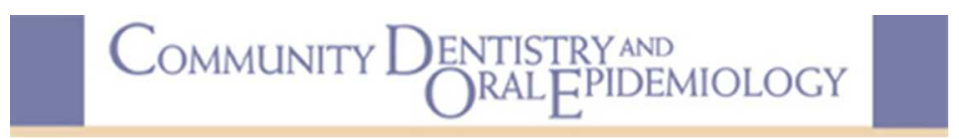

\title{
Payment systems and incentives in dentistry
}

\begin{tabular}{|c|c|}
\hline Journal: & Community Dentistry and Oral Epidemiology \\
\hline Manuscript ID & CDOE-16-291.R2 \\
\hline Manuscript Type: & Commentary \\
\hline Date Submitted by the Author: & $n / a$ \\
\hline Complete List of Authors: & Grytten, Jostein; University of Oslo, Institute of Community Dentistry \\
\hline Keywords: & $\begin{array}{l}\text { per capita remuneration, pay for-performance, remuneration, incentives, } \\
\text { fee-for-service }\end{array}$ \\
\hline Abstract: & $\begin{array}{l}\text { In this commentary, we discuss the advantages and disadvantages of the } \\
\text { following incentive-based remuneration systems in dentistry: fee-for-item } \\
\text { fee-for-service remuneration, per capita remuneration, a mixed payment } \\
\text { system (a combination of fee-for-item fee-for-service remuneration and } \\
\text { per capita remuneration) and pay-for-performance. The two latter schemes } \\
\text { are fairly new in dentistry. } \\
\text { Fee-for-item Fee-for-service payments secure high quality, but lead to } \\
\text { increased costs, probably due to supplier-induced demand. Per capita } \\
\text { payments secure effectiveness, but may lead to under-treatment and } \\
\text { patient selection. A mixed payment scheme produces results somewhere } \\
\text { between over- and under-treatment. The prospective component (the per } \\
\text { capita payment) promotes efficiency, while the retrospective component } \\
\text { (the fee-for-service payment) secures high quality of the care that is } \\
\text { provided. A pay-for-performance payment scheme is specifically designed } \\
\text { towards improvements in dental health. This is done by linking provider } \\
\text { reimbursements directly to performance indicators measuring dental health } \\
\text { outcomes and quality of the services. Experience from general health } \\
\text { services is that pay-for-performance payment has not been very } \\
\text { successul. This is due to significant design and implementation obstacles, } \\
\text { and lack of provider acceptance. } \\
\text { A major criticism of all the incentive-based remuneration schemes is that } \\
\text { they may undermine the dentists' intrinsic motivation for performing a } \\
\text { task. This is a crowding-out effect, which is particularly strong when } \\
\text { monetary incentives are introduced for care that is cognitively demanding } \\
\text { and complex, for example as in dentistry. One way in which intrinsic } \\
\text { motivation may not be undermined, is to introduce a fixed salary } \\
\text { component into the remuneration scheme. Dentists would then be able to } \\
\text { choose their type of contract according to their abilities and their } \\
\text { preferences for non-monetary rewards as opposed to monetary rewards. If } \\
\text { a fixed salary component cannot be introduced into the remuneration } \\
\text { scheme, the fees should be "neutral"; i.e. they should just cover the costs } \\
\text { of the services provided. This is one way in which supplier-induced demand } \\
\text { can be limited, and costs contained. }\end{array}$ \\
\hline
\end{tabular}




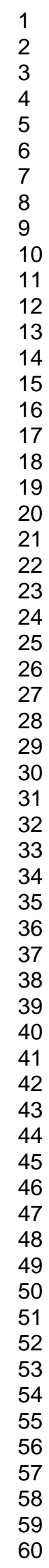

SCHOLARONE ${ }^{m}$

Manuscripts

Community Dentistry and Oral Epidemiology 


\title{
Payment systems and incentives in dentistry
}

\author{
Grytten Jostein \\ Department of Community Dentistry, \\ University of Oslo
}

Corresponding author:

Jostein Grytten

Department of Community Dentistry, University of Oslo

Post Box 1052, Blindern

0316 Oslo, Norway

E-mail: josteing@odont.uio.no

Telephone: +4722840387 


\begin{abstract}
In this commentary, we discuss the advantages and disadvantages of the following incentive-based remuneration systems in dentistry: fee-for-item fee-for-service remuneration, per capita remuneration, a mixed payment system (a combination of feefor-item fee-for-service remuneration and per capita remuneration) and pay-forperformance. The two latter schemes are fairly new in dentistry.

Fee-for-item Fee-for-service payments secure high quality, but lead to increased costs, probably due to supplier-induced demand. Per capita payments secure effectiveness, but may lead to under-treatment and patient selection. A mixed payment scheme produces results somewhere between over- and under-treatment. The prospective component (the per capita payment) promotes efficiency, while the retrospective component (the fee-for-service payment) secures high quality of the care that is provided. A pay-forperformance payment scheme is specifically designed towards improvements in dental health. This is done by linking provider reimbursements directly to performance indicators measuring dental health outcomes and quality of the services. Experience from general health services is that pay-for-performance payment has not been very successful. This is due to significant design and implementation obstacles, and lack of provider acceptance.

A major criticism of all the incentive-based remuneration schemes is that they may undermine the dentists' intrinsic motivation for performing a task. This is a crowdingout effect, which is particularly strong when monetary incentives are introduced for care that is cognitively demanding and complex, for example as in dentistry. One way in which intrinsic motivation may not be undermined, is to introduce a fixed salary component into the remuneration scheme. Dentists would then be able to choose their type of contract according to their abilities and their preferences for non-monetary rewards as opposed to monetary rewards. If a fixed salary component cannot be introduced into the remuneration scheme, the fees should be "neutral"; i.e. they should
\end{abstract}


just cover the costs of the services provided. This is one way in which supplier-induced demand can be limited, and costs contained.

Key words: fee-for-item Fee-for-service remuneration, per capita remuneration, pay forperformance, incentives, remuneration

Running head: Incentives and payment systems in dentistry 


\section{Background - types of payment system}

Economic theory and common sense both suggest that the way people are paid affects their working pattern. This is also the case for dentists. Historically, there have been three ways of paying for dental care: fee-for-service, salary and capitation ${ }^{1}$. Each of these payment systems creates very different incentives, and they each have their strengths and weaknesses. Often, attention has been directed towards the weaknesses. For this reason, during the last decade, there has been an increasing interest in modifying existing systems and developing new systems ${ }^{2}$. A new payment system that is emerging in dentistry is pay-for-performance ${ }^{3,4}$. There is also a trend towards combining different systems; for example, fee-for-service in combination with capitation.

In this commentary, we will give a brief overview of the most important payment systems as they relate to dentistry, and then describe the effects that the different models can have on dentists' behaviour. The advantages and disadvantages of the different models will be discussed. The issue is whether the different payment systems achieve their intended outcomes, such as access to high quality dental care and, probably just as importantly, whether they lead to unintended outcomes such as unnecessary treatment or the avoidance of care for patients with special needs ${ }^{5}$.

Health economics, which includes the topics of payment systems and incentives, has become a valuable discipline for studying market failures in health care. Analyses based on models from health economics are used more and more in dentistry, mainly as an aid to clinical and administrative decision making. Previous reviews deal with topics such as the structure and function of dental care markets, the role of dental insurance, economic determinants of oral health, including production of oral health, and economic evaluation $^{6-10}$. The present review fills a gap in the literature, by presenting a comprehensive overview of how dentists are influenced by type of payment system. 


\section{Fee-for-service and apple pickers}

Fee-for-service is the dominant form of payment both in dentistry and medicine. To illustrate the scope of the use of this payment system: in Medicare in the USA there are 7000 procedures that have their own fees ${ }^{11}$. In public and private insurance programmes fees are usually set administratively. In dental care markets without insurance programmes, fees are determined by market forces. Since dentists are paid a fee for every unit of care they deliver, their income is directly related to their level of activity.

Pure fee-for-service based payments, although highly prevalent, have come under widespread criticism. Decades ago, the well-known Professor of Economics Burton Weisbrod argued: "Payments based on the level of activity are suitable for paying apple pickers, but not physicians" ". For several reasons, it makes sense to use strong incentives for apple pickers: It is easy to measure whether they are delivering the desired product, and the cost of measurement is low. The product of apple picking is well defined and precise, so there is little concern that rewarding apple picking diverts attention away from other activities that an employer would want apple pickers to carry out $^{12}$.

In contrast, much of the work that dentists do is complex and highly dependent on the specific needs of each particular patient. We want dentists to use their knowledge, experience and skills to exercise sound judgment in their clinical decision making, and to do this in the best possible interest of the patients ${ }^{13}$. Further, any attempts to reward some activities run the risk of diverting dentists' attention away from other areas that could be important, but more difficult to measure, such as prevention ${ }^{14}$.

Because fees reward dentists for each type of service they provide, a fee-for-service payment system may encourage more treatment than is necessary ${ }^{15-17}$. Such unnecessary treatment may take different forms ${ }^{18}$ : 
a) Treatment which is not necessary at all; for example where a dentist fills a nonexistent cavity, or fills a small cavity where most dentists would wait to see if caries developed $^{19-21}$.

b) Cases where some treatment is necessary, but what is proposed is in excess of treatment which is considered necessary ${ }^{22-24}$.

c) Cases where the treatment is inappropriate; for example where the dentist prescribes treatment which requires the co-operation of the patient which the dentist has no reasonable expectation of receiving ${ }^{25-27}$.

The dividing line between what is too much treatment as opposed to appropriate treatment is often narrow, and may be difficult to determine in individual cases ${ }^{28}$. In addition, there may be lack of evidence and data in relation to what might be considered adequate levels of dental treatment. Therefore, in situations where the criteria for interventions are unclear and/or ambiguous, dentists have the possibility to provide more treatment than is necessary. This may occur because dentists are more concerned about their own economic interests rather than patients' welfare. This is known as supplierinduced demand, and it is considered to be one of the major weaknesses of a fee-forservice payment system. Supplier-induced demand is commonly studied using agency theory as the guiding theoretical framework ${ }^{29}$.

The basic idea of agency theory is that the dentist acts on behalf of the patient. Ideally, the dentist should act only in the patient's best interest. In certain situations this may be difficult, because sometimes the dentist is motivated to act in his/her own interests, rather than those of the patient ${ }^{29,30}$. An ideal payment system neutralizes the dentist's self-interest - this is eliminated from "the picture". The patient's welfare is then maximized. 


\section{Fee-for-service and dentist's self-interest}

The background for the hypothesis on supplier-induced demand is the assumption of asymmetric information between the dentist and the patient. The patient does not have sufficient expertise to evaluate the extent and quality of the services supplied. Therefore, the dentist has two roles: to act as the patient's adviser and to offer dental care. In the role of adviser, he or she has a considerable influence on the type and quality of services offered. Since the patient is poorly informed, the dentist has the possibility to influence the amount of supervision and care provided. He or she can also influence the number of consultations by deciding on the recall interval. Competition for patients can influence the dentist's economic incentives. The question is whether competition influences the dentist's behaviour such that he or she induces demand for dental treatment. If this is the case, then this leads to increased costs for the patient and for society as a whole. There are few studies on supplier-induced demand in dentistry. The studies that exist support the supplier inducement hypothesis ${ }^{15,16,31-33}$. Typically, they find an increase in the cost per visit as the supply of dentists increases.

The mechanisms behind supplier inducement are shown in Fig. $1^{34}$. Let us assume a competitive market where fees are determined by market forces. The figure shows the relationship between dental fees and the amount of dental services demanded. Increased competition for patients, for example, if a new dentist moves into a certain geographical area, means that fees fall from $F_{0}$ to $F_{1}$. Lower fees are then meant to lead to an increase in quantity from $\mathrm{Q}_{0}$ to $\mathrm{Q}_{1}$. The increase in consumption occurs as a movement along the demand curve $\mathrm{D}_{0}$ (Fig. 1, top diagram). From a welfare economic aspect, this increase in the quantity demanded is considered to be acceptable. Patients consume more dental services because they have become cheaper, and competition has led to a reduction in fees.

The supply curves in Fig. 1 are vertical. They are perfectly price inelastic; i.e. the quantity supplied is unresponsive to price changes. They are drawn like this to simplify interpretation. The above conclusion does not change in the case of a price- 
elastic supply curve; i.e. when the quantity supplied is responsive to higher or lower prices.

Fig. 1, bottom diagram, also shows what happens if competition does not work under a fee-for-service payment system. Supply, in the form of new dentists establishing a practice in a geographical area, also increases here from $S_{0}$ to $S_{1}$. However, this increase in supply is not followed by a corresponding reduction in fees. Competition means that the dentist's income is threatened. The dentists counteract a fall in income by increasing the quantity of services provided and by increasing their fees. In Fig. 1, bottom diagram, this is illustrated by the dentists moving the demand curve outwards from $\mathrm{D}_{0}$ to $\mathrm{D}_{1}$. The amount consumed also increases from $\mathrm{Q}_{0}$ to $\mathrm{Q}_{1}$, as in the above figure. But this increase in quantity has not occurred as a result of a reduction in fees. Rather, it is the result of failure of competition. New dentists have been able to establish a practice, without this leading to a corresponding pressure to reduce fees. This leads to increased costs for dental services, as illustrated by the shaded area in Fig. 2, bottom diagram. Costs are defined as fees multiplied by quantity; i.e. the amount of dental services provided. In Fig. 2, the shaded area in the bottom diagram (induced demand) is larger than the shaded area in the top diagram (no inducement).

The induced demand as illustrated in Fig. 1, bottom diagram, is so high that fees are raised above their initial levels. Clearly, a lesser form of inducement is possible whereby the inducement results in a new equilibrium fee below the old one but above what it would be without inducement ${ }^{35}$. In that case the demand curve does not move as far out as illustrated on Fig. 1, bottom diagram.

When the concept of supplier-induced demand was introduced in the 1970s and 1980s, it had negative connotations - provision of services that were ineffective, and thus wasteful or even harmful ${ }^{36-38}$. During the last few decades, this view has been modified. It has been argued that supplier-induced demand is less of a problem as long as the extra utilization (i.e. the extra costs) leads to improvements in health ${ }^{39-41}$. Yet there are no studies in which the relationship between increased utilization due to the contribution of 
supplier inducement to the health status of patients has been examined. Such studies are not easy to carry out. This is partly because many of the clinical procedures and interventions used in health care, dental care included, have not been subjected to clinical evaluation $^{42,43}$. For procedures and interventions where clinical effectiveness has been proven, supplier inducement may be beneficial. However, this would only be the case if the extra costs of the services provided due to inducement are less than the benefits to health ${ }^{39,40,44,45}$.

In order to contain costs, two alternative payment systems are commonly suggested: pay for performance and per capita payment ${ }^{46,47}$. A prerequisite for the use of both these payment systems is a reasonably strong third-party payer, in principle either public or private insurance schemes.

\section{Pay-for-performance - cost containment by targeting provider reimbursements}

Fee-for-service payments are associated with a high level of utilization, without that necessarily leading to better health outcomes ${ }^{46,48}$. Pay-for-performance is meant to remedy this weakness. This is done by linking provider reimbursements directly to performance indicators measuring health outcomes and the quality of the services ${ }^{47}$. Providers are paid for "doing the right thing, at the right time, in the right way, delivered to the right patient" ${ }^{49}$. In the long run, it is accepted that this will lead to a reduction in the growth of health care costs. In the beginning, pay-for-performance was often implemented as a mandatory programme with financial penalties for not achieving the targets. This became very unpopular among providers, hence the focus today is on rewarding providers if targets are met $^{4}$.

During the last two decades, interest in applying pay-for-performance to health care has greatly increased. Pay-for-performance has been adopted as a key strategy among public purchasers (Medicare) and private purchasers (MCOs) in the USA, and within national 
health services in several European countries ${ }^{50-52}$. For example, in Medicare in the USA, there are more than 100 performance indicators where physicians are rewarded if targets are met $^{50}$. In 2003 the British National Health Service implemented probably the most ambitious pay-for-performance programme in the world ${ }^{53,54}$. More than 100 targets were set and sizeable payments to physicians who achieved the targets were made. Altogether about $80 \%$ of family practitioners' activities were covered by performance indicators.

The programme acceptance was high, and nearly all the practitioners reached the targets; i.e. the financial incentives worked.

Despite its widespread use, there is no clear evidence that health outcomes, or even the quality of services, has improved ${ }^{47,55-60,61}$. There are several reasons; the most important is probably that it is difficult to identify the type of indicators that lead to improvements in health. Further, numerous studies have shown that several programmes suffer from significant design and implementation obstacles, and lack of provider acceptance.

Despite these problems, pay-for-performance continues to expand in medicine.

Although initially designed for medical care, pay-for-performance can also be considered for dentistry. However, it is not used very much. One exception is that pilot studies have been conducted in the National Health Service in England. In these studies, one element of dentists' remuneration was based on dentists' performance according to indicators of quality ${ }^{62,63}$.

History has shown that the dental profession often follows in the footsteps of medicine ${ }^{3}$. If evidence can be provided that pay-for-performance improves the quality of dental care and limits costs, then the case for its introduction would be strengthened. At the moment such evidence is lacking. Also, there are some obstacles that make implementation difficult.

One such obstacle is the lack of clinical markers that are valid indicators of the severity of dental diseases ${ }^{64}$. This is different from in medicine. For example, for the management of diabetes, the hemoglobin $\mathrm{A}_{1 \mathrm{c}}$ level is an established indicator of disease control. Similarly, blood pressure is used for hypertension control. Clinical indicators 
with a sufficiently high sensitivity and specificity do not exist for the management of dental caries and periodontitis ${ }^{65-67}$. Other quality indicators, such as psychosocial outcomes, also have low sensitivity and specificity. Thus, it is difficult to create performance indicators that are related in a meaningful way to the prevention and development of the two most prevalent diseases in dentistry: caries and periodontitis ${ }^{68-71}$.

Within dentistry there is an abundance of published research, but evidence about the effectiveness of many areas of treatment is lacking. For example, the Cochrane Collaborative Group has reviewed nearly 100 different types of diagnostic tools and treatment within dentistry ${ }^{64}$. They have found insufficient evidence for many of them. This is partly the reason why there are few widely accepted guidelines in dentistry.

For a pay-for-performance programme to be successful, the following criteria should be fulfilled: the objectives have to be clear, the performance indicators need to be valid, the analysis and the interpretation of the performance data need to be unambiguous and provider acceptance needs to be high ${ }^{47,72}$. At the moment, a pay-for-performance programme with these characteristics cannot easily be designed in dentistry. Therefore, our guess is that it will still take some time until such programmes are implemented on a large scale.

\section{Per capita payment and cost containment}

With a purely per capita contract, the dentist gets a set sum for each person he or she has responsibility for providing dental services to. This is also the strength of a per capita contract - dentists who wish to work a lot get rewarded for their efforts. In other words, a per capita contract leads to higher production per dentist ${ }^{1}$. This has implications for dental education policy. Under per capita remuneration fewer dentists would be needed, and therefore fewer dentists would need to be trained, leading to savings.

Since the money follows the patient, independent of the amount of care provided, capitation is meant to contain costs per patient, but might lead to underprovision of 
services, i.e. dentists may under-treat patients in order to save costs. Further, patient selection is a potential problem. Since dentists get a fixed fee per patient under supervision, it pays to have responsibility for many healthy patients. This gives a high remuneration with little effort ${ }^{48}$.

One possible way in which under-treatment and patient selection can be limited is risk adjustment of the per capita fee. If patient groups with high treatment need can be identified according to a few observable characteristics, then these characteristics can be used in order to differentiate the per capita fee. However, note that the differentiation must not be made on the basis of characteristics that the dentist can manipulate himself/herself, for example, level of dental disease. A higher per capita rate for patients with a lot of caries can seem like a good idea. However, the problem is that the dentist can be tempted to over-register caries in order to get a higher per capita fee.

It is difficult to find good indicators at the patient level that can differentiate between individuals with high and low levels of disease. Most indicators, such as age and gender, have relatively low sensitivity and specificity ${ }^{73-75}$. This has led economists to suggest a two-part or a mixed payment system ${ }^{11,46}$.

\section{Mixed payment system - the best of fee-for-service and per capita payment}

The underlying idea behind a mixed fee-for-service and a capitation payment is to avoid the adverse effects and to take advantage of the favourable effects of each system. Therefore, a mixed payment system may produce results somewhere between over- and under-treatment. The prospective component, i.e. the per capita payment, will promote efficiency, while the retrospective component, i.e. the fee-for-service payment, will secure the quality of the care that is provided $^{11}$.

How large should the per capita component be in comparison to the fee-for-service component? This will depend on the characteristics of the population being served. For 
example, in most Western European countries, the majority of children and adolescents have good dental health, with few treatment needs. Within such a population, the per capita payment should be large ${ }^{76}$. That will lead to high productivity, which is what we want. Conversely, the fee-for-service payment should be large in a population of elderly people ${ }^{77}$. That will reduce the risk of patient selection and under-treatment.

\section{Incentive-based payment systems weaken intrinsic motivation}

The three types of incentive-based payment system discussed so far have a strong intuitive appeal, as they link output directly to monetary rewards. This follows from the traditional view of economists that monetary rewards are the key motivating factor for performing a task: performance rises with payment. This view of economists is in conflict with the view of psychologists, who emphasise that intrinsic motivation may be just as important as external extrinsic motivation ${ }^{5,56,78,79}$. Intrinsic motivation refers to the desire to perform an activity for its own inherent rewards ${ }^{78}$. It refers to incentives that are unrelated to profit. Typically, intrinsic motivation is related to activities that the dentist considers inherently interesting and challenging.

A large amount of experimental evidence from psychology shows that when an activity is driven by intrinsic motivation, such as professionalism, or pride in the quality of one's work, then adding a financial motive might undermine, or "crowd out", intrinsic motivation ${ }^{5,78-80}$. This reduces the incentive effect from monetary rewards. In the worst case, crowding out may lead to less production rather than more. This would be the case if intrinsic motivation is high and the crowding out effect is strong.

There are several theories about how monetary rewards can undermine intrinsic motivation ${ }^{5}$. One mechanism is by questioning one's sense of autonomy and competence, which may result in poorer performance. Further, monetary rewards may be perceived as being controlling, with the implication that professionals take less responsibility for 
motivating themselves. The desire to perform well may also be weakened when it is no longer one's own idea to perform well.

The "crowding-out effect" is particularly strong when monetary incentives are introduced for care that is cognitively demanding and complex, because such work is often inherently challenging and interesting ${ }^{81,82}$. This could be the case for medicine and dentistry. For simple, repetitive tasks, financial incentives work just as economic theory predicts $^{79,80}$. For these types of task, intrinsic motivation cannot be undermined, since it hardly exists at the outset.

Within the field of medicine, empirical research on "crowding-out" effects is just starting. Probably, so far, the most promising research has been done by Jonathan Kolstad, who recently won the Arrow Award in Health Economics for his work on the role of intrinsic motivation in providing high quality hospital care ${ }^{83}$. The study was performed in two steps. First, he estimated how heart surgeons in Pennsylvania responded to information about the quality of their CABG surgery, measured as the mortality rate of their patients. This information was not made available to the public or potential patients. The estimated response from this first analysis is a measure of intrinsic motivation. Second, he measured how surgeons responded when the information was also made available to the public or potential patients. This is a measure of both intrinsic and extrinsic motivation. Here, the issue is to what extent surgeons changed their clinical behaviour due to a loss of their market share for patients. All the analyses were performed on a set of data encompassing nearly 100,000 surgical procedures during the period 1994 to 2003. In his paper, Jonathan Kolstad (2013) concludes: "the intrinsic response to quality information leads to a significant decline in mortality rates and is large relative to the response from monetary rewards" ${ }^{\prime \prime 3}$. In fact, his analyses showed that the intrinsic response was four times as large as the extrinsic response.

To our knowledge, within dentistry, there has been no research on "crowding-out" effects. However, the evidence from the field of psychology and from the work of 
Jonathan Kolstad has relevance for dentistry ${ }^{79,80,83}$. This is particularly so for fee-for service and pay-for-performance contracts. Both these types of contract, fee-for-service in particular, are based on a high level of contractual detail - a too high level some would argue. Not every aspect of dentists' work is measurable. Often, it is more or less impossible to make an airtight agreement between dentists and patients/insurance companies where all details with respect to dental treatment can be specified in advance. The more aspects of performance above the necessary minimum that are measured, the stronger the "crowding-out effect" is likely to be. Unnecessary measuring will easily undermine the dentists' sense of autonomy, and be perceived as being unnecessarily controlling. With respect to contractual detail, more may not be better. In fact, it may even be worse: if something is omitted from a detailed contract, dentists may not necessarily do the work. One may end up with a system where dentists would only do something because they are paid for it, not because they are professionally and ethically obliged to do it. In such a situation the quality of the work dentists do may suffer; for example by dentists not using their competence to fully benefit their patients ${ }^{3,4}$. This is a potential danger with detailed fee-for-service and pay-for-performance contracts ${ }^{13}$.

\section{Rewards under the control of the dentist - the advantages of flexible contracts}

Is there any way in which payment systems can be designed so that intrinsic motivation is not undermined? One approach is as much as possible to make the amount of rewards, and hence income, under the direct control of the dentists. This can be done by offering a set of flexible types of contract, and then letting the dentists' choose their type of contract according to their preferences and abilities ${ }^{84}$. The idea is to allow dentists to keep their sense of autonomy and to avoid making them feel too much controlled. As an example, let us illustrate how this works in the case of a fixed salary versus a per capita contract. The train of thought and the conclusion presented at the end also holds in the case of a fixed salary versus a fee-for-service payment system. The theoretical 
framework for this analysis has been developed by the award-winning American economist Edward P. Lazear, who has written numerous papers and books on the topic ${ }^{85-}$ 87

The trade-offs that two hypothetical dentists are prepared to accept between how hard they work and how much they are paid are represented in Fig. 3. The indifference curves represent dentists with different preferences. The curves slope upwards because output requires effort, while income is a good. Thus dentists who put in more effort must be compensated with more income in order to be indifferent. Consider two types of dentist. One type is ambitious and prefers to work more, earn more, and have less leisure time. The other type is not so ambitious, prefers to work less, earn less and have more leisure time. The dentist with high ambition has an indifference curve that is not as steep (dotted lines). He or she is less averse to work, and additional effort can be compensated for by a smaller increase in income. The dentist with low ambition has a steep indifference curve, because additional effort must be compensated for by a large increase in income, as indicated by the solid indifference line through A.

A payment system based on fixed salary is shown by a function that starts at zero, becomes vertical at $\mathrm{e}_{0}$ and then horizontal at point $\mathrm{A}$. $\mathrm{e}_{0}$ represents the minimum level of output that must be produced in order keep one's job. If the dentists are offered a fixed salary only, they are most likely to choose to work at point A, since there is no financial reward for putting in more effort. Then they will be paid a set hourly wage.

The per capita payment scheme is the same as the fixed salary scheme up to $\mathrm{e}^{*}$, but then compensation rises with output, as shown by the solid, positively-sloped line. When dentists can choose between an incentive-based payment system and a fixed salary scheme, the less ambitious dentist still chooses point A, while the more ambitious dentist chooses point $\mathrm{B}$. Then the satisfaction of the more ambitious dentist has increased, while the satisfaction of the less ambitious dentist is unaltered. Dentists have been able to choose their type of contract according to their abilities and their preferences for nonmonetary rewards as opposed to monetary rewards. The fact that dentists are not an 
homogenous group has been taken into account. They are not forced to work under the same remuneration system. This makes it less likely that their intrinsic motivation is undermined.

What about the effectiveness under a payment system with flexible contracts? It depends on the point of departure. If all dentists were originally paid a fixed salary, then the total supply of services would increase when dentists are offered an incentive-based type of contract. The mean increase per dentist for those who change their type of contract is equal to the distance $e_{0}-e_{1}$ in Fig. 3. On the other hand, if the point of departure is that all dentists originally were offered a fee-for-service contract, then total supply would decrease when dentists were offered a fixed salary contract. The benefits would be that satisfaction and probably internal motivation would have increased for dentists who were given the opportunity to be paid a fixed salary.

\section{The lack of third-party payers makes fee-for-service payments unavoidable}

With the exception of fee-for-service, the other payment systems require a strong thirdparty payer, for example a public or private insurance scheme. Dentistry is different from medicine in that third-party payers are not that common. This is the reason why, in most countries, fee-for-service is the dominant payment system within dentistry. This is particularly so in countries that have primarily based their welfare services on private solutions and supply. With fee-for-service financing, the dentist is remunerated according to the actual cost of the treatment. In that way it is easier to ensure quality with this system than with a per capita system. However, the challenge with a fee-forservice system is cost control, mainly due to supplier inducement (Fig. 2, bottom diagram $)^{15,16}$. How can this adverse side effect be reduced to a minimum?

First, it is important to establish a culture among dentists that focuses on the ethical aspects of service provision ${ }^{34}$. Norms should be established within the organization that 
counteract any tendency for dentists to be tempted to achieve financial gains at the expense of the patient. The authorities have a role in terms of supervision and continual monitoring of the quality of the services provided, and hopefully this will also have an effect on the behaviour of the individual dentist.

Second, if possible, the authorities should try to implement a "neutral" fee-for-service payment system ${ }^{11}$. In such a system the fee covers just the costs of the service provided. An economically neutral payment system has the potential to take dentists' self-interest out of the picture by paying the exact cost for each item of treatment. In such a system marginal revenue is equal to marginal cost. This approach, with "neutral" fees, is only possible within a system with administered set fees, set either by a public or private insurance scheme. Even with neutral fees, fee-for-service payments are made on the basis of the volume of services delivered ${ }^{11}$.

Pay-for-performance is an alternative to a fee-for-service payment system. Pay-forperformance is based on value-based pricing, where value is defined as health outcomes achieved per monetary unit spent ${ }^{88-90}$. With pay-for-performance, focus is shifted from volume to value. Within dentistry, measuring value is a challenge, partly because evidence about the effectiveness of many types of dental treatment is lacking.

\section{Conclusion}

The available evidence shows that providers respond to incentives, both monetary and non-monetary rewards. The strength of the response and the extent of unintended consequences both depend on the context in which incentives are introduced and the design of the incentive programme. In practice, dentists, administrators and policymakers seldom plan a dental service "from scratch", but must relate to the financing systems that already exist within the established services. To a large extent the existing systems are determined by the institutional, historical and political contexts in which the dental services in the different countries have developed. However, whatever 
system, the adverse side-effects of each type of financing system should be reduced to a minimum. The possibility to succeed in that respect is to offer dentists a flexible type of contract in which a fixed salary component forms part of the contract. Unfortunately, such contracts are only feasible within an organization with a strong third-party payer.

\section{Acknowledgements}

We wish to thank Linda Grytten for language correction and Irene Skau for useful comments and technical assistance. 


\section{References}

1. Brocklehurst P, Price J, Glenny AM, Tickle M, Birch S, Mertz E, et al. The effect of different methods of remuneration on the behaviour of primary care dentists (Review). Cochrane Database of Systematic Reviews, 2013, Issue 11. DOI: 10.1002/14651858.CD009853.pub2.

2. Holmes RD, Steele JG, Donaldson C, Exley C. Learning from contract change in primary care dentistry: a qualitative study of stakeholders in the north of England. Health Policy 2015; 119: 1218-25.

3. Voinea-Griffen A, Fellows JL, Rindal DB, Barasch A, Gilbert GH, Safford MM. Pay for performance: will dentistry follow? BMC Oral Health 2010; 10: 9. DOI: $10.1186 / 1472-6831-10-9$.

4. Voinea-Griffin A, Rindal B, Fellows JL, Barasch A, Gilbert GH, Safford MM. Payfor-performance in dentistry: what we know. J Healthc Qual 2010; 32: 51-8.

5. Kao AC. Driven to care: aligning external motivators with intrinsic motivation. Health Serv Res 2015; 50: 2216-20.

6. Grembowski D, Conrad D, Weaver M, Milgrom P. The structure and function of dental-care markets. Med Care 1988; 26: 132-47.

7. Sintonen H, Linnosmaa I. Economics of dental services. In: Culyer AJ, Newhouse JP, editors: Handbook of Health Economics, Volume 1, part B. Amsterdam: Elsevier, 2000; 1251-96.

8. Birch S, Listl S. The economics of oral health and health care. MEA Discussion paper 07-2015. Available at:

http://mea.mpisoc.mpg.de/index.php?id=216\&no cache $=1 \&$ tx ttnews $\% 5 \mathrm{Btt} \mathrm{n}$ $\underline{\text { ews } \% 5 D=279 \& c H a s h=28 b c 429 b 896273 f 5 b c 4098802901 d 2 d 4}$. (September 15, 2016). 
9. Yule B, Parkin D. The demand for dental care: an assessment. Soc Sci Med 1985; $21: 753-60$.

10. Shariati B, MacEntee MI, Yazdizadeh M. The economics of dentistry: a neglected concern. Community Dent Oral Epidemiol 2013; 41: 385-94.

11. McGuire TG. Physician agency and payment for primary medical care. In: Glied S, Smith PC, editors: The Oxford handbook of health economics. Oxford: Oxford University Press, 2011; 602-23.

12. Kronick R, Casalino LP, Bindman AB. Apple pickers or federal judges: strong versus weak incentives in physician payment. Health Serv Res 2015; 50: 2049-56.

13. Wynia MK. The risk of rewards in health care: how pay-for-performance could threaten, or bolster, medical professionalism. J Gen Intern Med 2009; 24: 884-7.

14. Birch S. Paying for prevention in clinical practice: aligning provider remuneration with system objectives. BMC Oral Health 2015; 15: S7. DOI: 10.1186/1472-683115-S1-S7.

15. Grytten J, Holst D, Laake P. Supplier inducement. Its effect on dental services in Norway. J Health Econ 1990; 9: 483-91.

16. Birch S. The identification of supplier-inducement in a fixed price system of health care provision. The case of dentistry in the United Kingdom. J Health Econ 1988; 7: 129-50.

17. Listl S, Chalkley M. Provider payment bares teeth: Dentist reimbursment and the use of check-up examinations. Soc Sci Med 2014; 111: 110-16.

18. Department of Health and Social Security. Report of the Committee of Enquiry into Unnecessary Dental Treatment. London: Her Majesty’s Stationary Office, 1986.

19. Zadik Y, Levin L. Clinical decision making in restorative dentistry, endodontics, and antibiotic prescription. J Dent Educ 2008; 72: 81-6. 
20. Tan PLB, Evans RW, Morgan MV. Caries, bitewings, and treatment decisions. Aust Dent J 2002; 47: 138-41.

21. Grembowski D, Fiset L, Milgrom P, Conrad D, Spadafora A. Does fluoridation reduce the use of dental services among adults? Med Care 1997; 35: 454-71.

22. Naegele ER, Cunha-Cruz J, Nadanovsky P. Disparity between dental needs and dental treatment provided. J Dent Res 2010; 89: 975-9.

23. Simonsen RJ. Commerce versus care: troubling trends in the ethics of esthetic dentistry. Dent Clin N Am 2007; 51: 281-7.

24. Kelleher M. Ethical issues, dilemmas and controversies in 'cosmetic' or aesthetic dentistry. A personal opinion. Br Dent J 2012; 212: 365-7.

25. Maihofer M. Over-treatment of elderly patients. J Mich Dent Assoc 2014; 96: 24, 74.

26. Käyser AF, Witter DJ, Spanauf AJ. Overtreatment with removable partial dentures in shortened dental arches. Aust Dent J 1987; 32: 178-82.

27. Hasegawa TK Jr. Overtreatment or appropriate treatment? Tex Dent J 2011; 128: 754-9.

28. Pauly M. What is unneccesary surgery? Milbank Mem Fund Q Health Soc 1979; 57: 95-117.

29. McGuire TG, Pauly MV. Physician response to fee changes with multiple payers. J Health Econ 1991; 10: 385-410.

30. Chalkley M, Tilley C, Young L, Bonetti D, Clarkson J. Incentives for dentists in public service: evidence from a natural experiment. J Public Adm Res Theory 2010; 20: $1207-23$.

31. Schaafsma J. A new test for supplier-inducement and application to the Canadian market for dental care. J Health Econ 1994; 13: 407-31. 
32. Grytten J. The effect of supplier inducement on Norwegian dental services; some empirical findings based on a theoretical model. Community Dent Health 1991; 8: 221-31.

33. Sintonen H, Maljanen T. Explaning the utilisation of dental care. Experiences from the Finnish dental market. Health Econ 1995; 4: 453-66.

34. Grytten J. Models for financing dental services. A review. Community Dent Health $2005 ; 22: 75-85$.

35. Reinhardt UE. Comment on a paper by Sloan \& Feldman. In: Greenberg W, editor: Competition in the health care sector: past, present, and future. Washington D.C.: Federal Trade Commision, 1978: 156-90.

36. Evans RG. Supplier-induced demand: some empirical evidence and implications. In: Perlman M, editor: The economics of health av medical care. Edinburgh: Macmillan, 1974: $162-73$.

37. Wilensky GR, Rossiter LF. The relative importance of physician-induced demand in the demand for medical care. Milbank Mem Fund Q Health Soc 1983; 61: 252-77.

38. Rice TH, Labelle RJ. Do physicians induce demand for medical services? J Health Polit Policy Law 1989; 14: 587-600.

39. Labelle R, Stoddart G, Rice T. A re-examination of the meaning and importance of supplier-induced demand. J Health Econ 1994; 13: 347-68.

40. Pauly M. Editorial: A re-examination of the meaning and importance of supplierinduced demand. J Health Econ 1994; 13: 369-72.

41. Hadley J, Holahan J, Scanlon W. Can fee-for-service reimbursement coexists with demand creation? Inquiry 1979; 16: 247-58.

42. Wennberg JE. Tracking Medicine. A researcher's quest to understand health care. New York: Oxford University Press, 2010. 
43. Scott A, Maynard A, Elliott R, editors. Advances in Health Economics. Chichester: Wiley, 2003.

44. Culyer AJ, Evans RG. Mark Pauly on welfare economics: normative rabbits from positive hats. J Health Econ 1996; 15: 243-51.

45. Feldman R. What does the demand curve for medical care measure? J Health Econ 1993; 12: 193-200.

46. Gosden T, Forland F, Kristiansen IS, Sutton M, Leese B, Giuffrida A, et al. Capitation, salary, fee-for-service and mixed systems of payment: effects on the behaviour of primary care physicians (Review). Cochrane Database of Systematic Reviews, 2000, Issue 3. DOI: 10.1002/14651858.CD002215.

47. Van Herck P, De Smedt D, Annemans L, Remmen R, Rosenthal MB, Sermeus W. Systematic review: effects, design choices, and context of pay-per-performance in health care. BMC Health Serv Res 2010; 10: 247. DOI: 10.1186/1472-6963-10247.

48. Robinson JC. Theory and practice in the design of physician payment incentives. Milbank Q 2001; 79: 149-77.

49. Agency for Healthcare Research and Quality. Your guide to choosing quality health care. Available at: http://archive.ahrq.gov/consumer/qntascii/qntcover.htm (September 15, 2016).

50. Institute of Medicine. Rewarding provider performance. Aligning incentives in medicine. Washington: National Academies Press, 2007. Available at: http://www.nap.edu/catalog/11723.html (September 15, 2016).

51. Rosenthal MB, Landon BE, Normand SLT, Frank RG, Epstein AM. Pay for performance in commercial HMOs. N Engl J Med 2006; 355: 1895-1902.

52. Eijkenaar F. Pay for performance in health care: an international overview of initiatives. Med Care Res Rev 2012; 69: 251-76. 
53. Doran T, Fullwood C, Gravelle H, Reeves D, Kontopantelis E, Hiroeh U, et al. Payfor-performance programs in family practices in the United Kingdom. N Engl J Med 2006; 355: 375-84.

54. Shekelle P. New contract for general practitioners. BMJ 2003; 326: 147-8.

55. Houle SKD, McAlistar FA, Jackevicius CA, Chuck WA, Tsuyuki RT. Does performance-based remuneration for individual health care practitioners affect patient care? Ann Intern Med 2012; 157: 889-99.

56. Himmelstein DA, Ariely D, Woolhandler S. Pay-for-performance: toxic to quality? Insights from behavioral economics. Int J Health Serv 2014; 44: 203-14.

57. Woolhandler S, Himmelstein D, Ariely D, Hellander I. Performance pay for physicians may backfire: BMJ editorial. Published in Physicians for a National Health Programme. Available at: http://www.pnhp.org/news/2012/august/ performance-pay-for-physicians-may-backfire-bmj-editorial (September 15, 2016).

58. Chen TT, Chung KP, Lin IC, Lai MS. The unintended consequence of diabetes mellitus pay-for-performance $(\mathrm{P} 4 \mathrm{P})$ program in Taiwan: are patients with more comorbidities or more severe conditions likely to be excluded from the P4P program? Health Serv Res 2011; 46: 47-60.

59. Layton TJ, Ryan AM. Higher incentive payments in Medicare advantage's pay-forperformance program did not improve quality but did increase plan offerings. Health Serv Res 2015; 50: 1810-28.

60. Gravelle H, Sutton M, Ma A. Doctor behaviour under pay performance contract: treating, cheating and case finding? Econ J 2010; F129-56.

61. Ryan AM, Krinsky S, Kontopantelis E, Doran T. Long-term evidence for theeffect of pay-for-performance in primary care on mortality in the UK: a population study. Lancet 2016; 388: 268-74. 
62. Department of Health. Dental quality and outcomes framework. 2011. Available at: https://www.gov.uk/government/publications/dental-quality-and-outcomesframework (September 15, 2016).

63. Department of Health. Dental contract reform: prototypes. Overview document. 2015. Available at: https:/www.gov.uk/government/uploads/system/uploads/ attachment_data/file/395384/Reform_Document.pdf (September 15, 2016).

64. Cochrane Oral Health. Available at: http://oralhealth.cochrane.org (September 15, 2016).

65. Bader JD, Shugars DA, Bonito AJ. Systematic reviews of selected dental caries diagnostic and management methods. J Dent Educ 2001; 65: 960-8.

66. Cobb CM. Clinical significance of non-surgical periodontal therapy: an evidencebased perspective of scaling and root planing. J Clin Periodontol 2002; 29: 22-32.

67. Brothwell DJ, Jutai DK, Hawkins RJ. An update of mechanical oral hygiene practices: evidence-based recommendations for disease prevention. J Can Dent Assoc 1998; 64: 295-306.

68. Ismail AI, Bader JD. How do I document all the benefits of dental care? J Am Dent Assoc 2000; 131: 1342-4.

69. Ismail AI, Bader JD. Evidence-based dentistry in clinical practice. J Am Dent Assoc 2004; 135: 78-83.

70. Richards D, Lawrence A. Evidence based dentistry. Evid Based Dent 1998; 1: 7-10.

71. McGlone P, Watt R, Sheiham A. Evidence-based dentistry: an overview of the challenges in changing professional practice. Br Dent J 2001; 190: 636-9.

72. Rosenthal MB, Dudley RA. Pay-for-performance. Will the latest payment trend improve care? JAMA 2007; 297: 740-4. 
73. Bader JD, editor. Risk assessment in dentistry. Chapel Hill: University of North Carolina Dental Ecology, 1990.

74. Hausen H. Caries prediction. In: Thystrup A, Fejerskov O, editors: Textbook of clinical cariology, $2^{\text {nd }}$ edition. Copenhagen: Munksgaard, 1996; 327-41.

75. Sheiham A. Screening for periodontal disease. J Clin Periodontol 1978; 5: 237-45.

76. Grytten J, Holst D, Skau I. Per capita remuneration of dentists and the quality of dental services. Community Dent Oral Epidemiol 2013; 41: 395-400.

77. Grytten J, Holst D. Perspectives on providing good access to dental services for elderly people: patient selection, dentists' responsibility and budget management. Gerodontology 2013; 30: 98-104.

78. Woolhandler S, Ariely D. Will pay for performance backfire? Insights from behavioral economics. Health Affairs Blog. 2012, 11 October. Available at: http://healthaffairs.org/blog/2012/10/11/will-pay-for-performance-backfire-insightsfrom-behavioral-economics/ (September 15, 2016).

79. Deci EL, Koestner R, Ryan RM. A meta-analytic review of experiments examining the effects of extrinsic rewards on intrinsic motivation. Psychol Bull 1999; 125 : 627-68.

80. Jenkins GD, Mitra A, Gupta N, Shaw JD. Are financial incentives related to performance? A meta-analytic review of empirical research. J Appl Psychol 1998; 83: $777-87$.

81. Glasziou PP, Buchan H, Del Mar C, Doust J, Harris M, Knight R, et al. When financial incentives do more good than harm: a checklist. BMJ 2012; 345: e5047. DOI: $10.1136 / \mathrm{bmj} . e 5047$.

82. Woolhandler S, Ariely D, Himmelstein DU. Why pay for performance may be incompatible with quality improvement. BMJ 2012; 345: e5015. DOI: 10.1136/bmj.e5015. 
83. Kolstad JT. Information and quality when motivation is intrinsic: evidence from surgeon report cards. Am Econ Rev 2013; 103: 2875-910.

84. Grytten J, Holst H, Skau I. Incentives and remuneration systems in dental services. Int J Health Care Finance Econ 2009; 9: 259-78.

85. Lazear EP. Personal economics: past lessons and future directions. J Labor Econ 1999; 17: 199-236.

86. Lazear EP. Salaries and piece rates. J Bus 1986; 59: 405-31.

87. Lazear EP. Personell economics for managers. New York: Wiley, 1998.

88. Porter ME. What is value in health care? N Engl J Med 2010; 363: 2477-81.

89. Porter ME. A strategy for health care reform - toward a value-based system. N Engl J Med 2009; 361: 109-12.

90. Conrad D, Grembowski D, Gibbons C, Marcus-Smith M, Hernandez SE, Chang J, et al. A report on eight early-stage state and regional projects testing value-based payment. Health Aff 2013; 32: 998-1006. 


\section{Captions:}

Fig. 1. A competitive market model (top) and a model with supplier-induced demand (bottom)

Fig. 2. Costs in a competitive market model (top) and in a model with supplier-induced demand (bottom)

Fig. 3. The relationship between compensation and output 

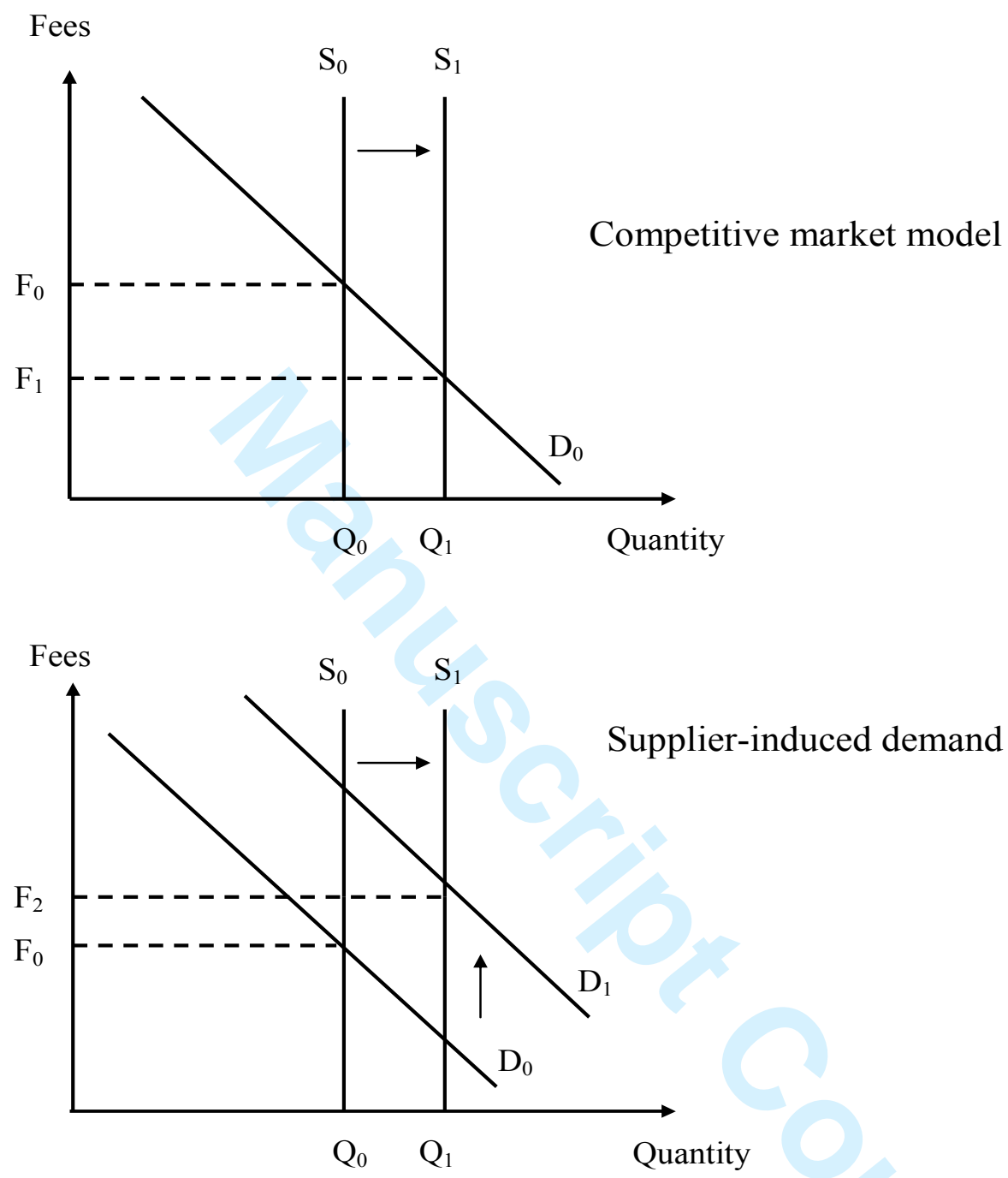

Fig. 1. A competitive market model (top) and a model with supplier-induced demand (bottom) 


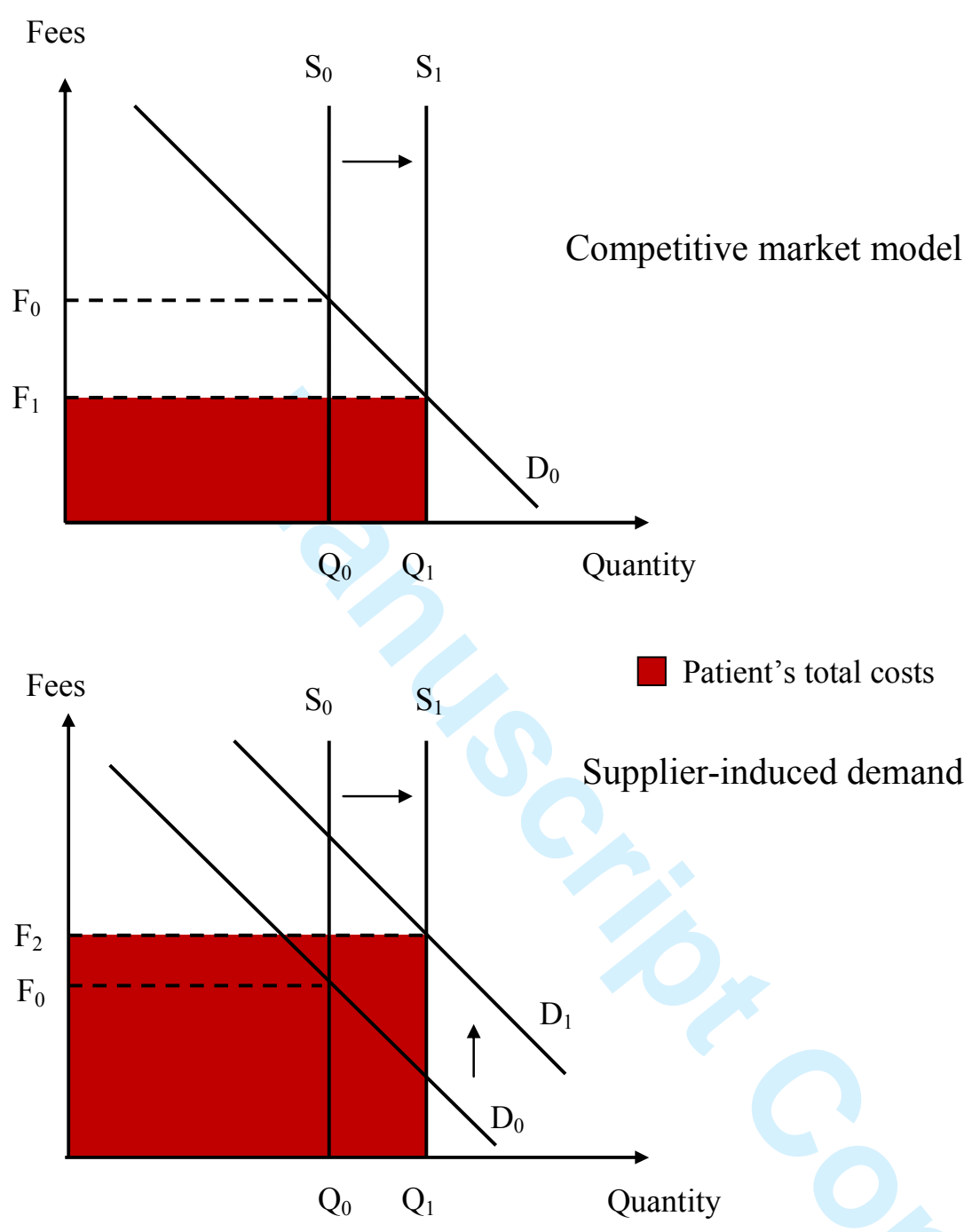

Fig. 2. Costs in a competitive market model (top) and in a model with supplier-induced demand (bottom) 

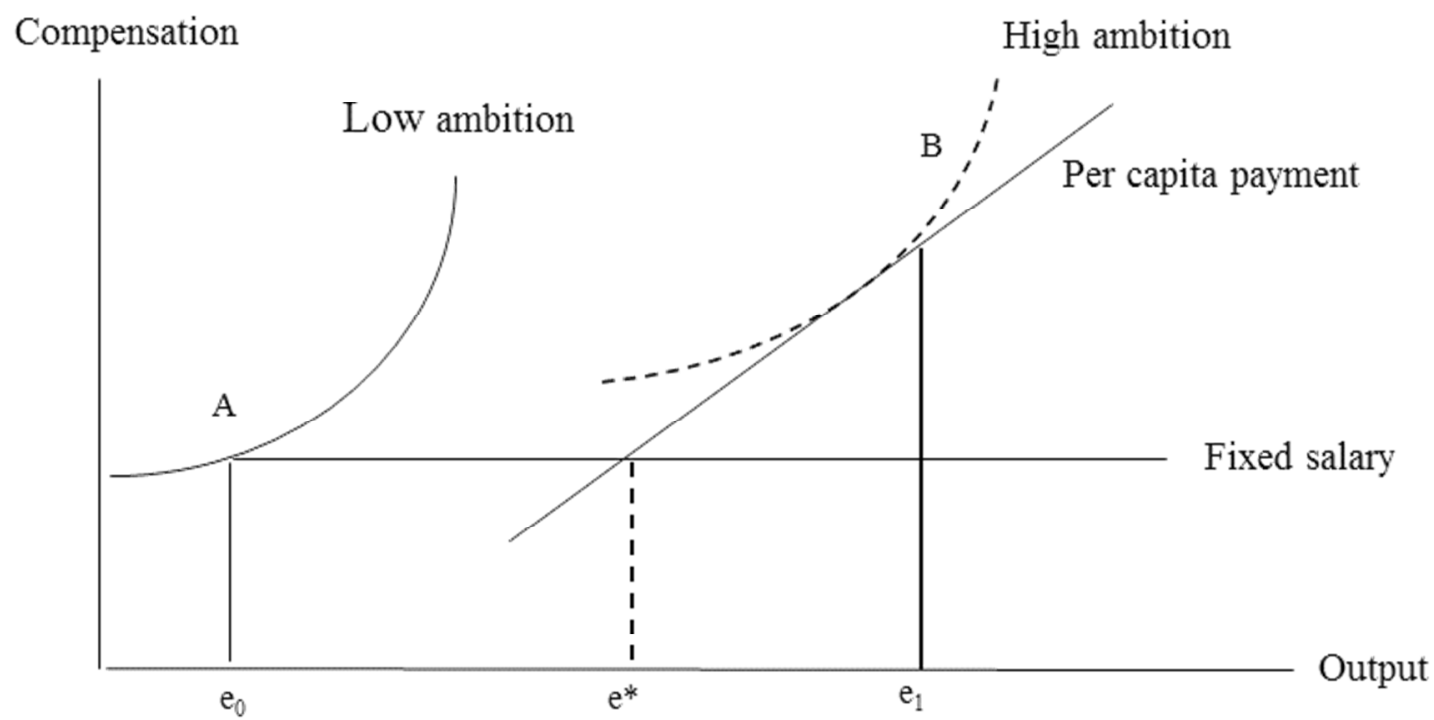

Fig.3. The relationship between compensation and output 